\title{
An Integrated Assessment of Investments towards Global Water Sustainability
}

\author{
Andrea M. Bassi ${ }^{1}{ }^{*}$, Zhuohua Tan ${ }^{1}$ and Sophie Goss ${ }^{1,2}$ \\ 1 Millennium Institute, 2111 Wilson Blvd. Suite 700, 22201 Arlington, VA, USA; \\ E-Mails: zt@ millennium-institute.org (Z.T.); sg@millennium-institute.org (S.G.) \\ 2 McGill University, 845 Sherbrooke St. W. Montreal, Quebec, H3A 2T5, Canada \\ * Author to whom correspondence should be addressed; E-Mail: ab@ millennium-institute.org; \\ Tel.: +1-571-721-8275; Fax: +1-703-351-9292.
}

Received: 12 September 2010; in revised form: 29 September 2010 / Accepted: 14 October 2010 / Published: 18 October 2010

\begin{abstract}
To date there has been limited research on integrated water resource management, specifically regarding investments, from a global perspective, largely due to the complexity of the problem and to generally local water management practices. Water demand and supply are very often affected by international factors and with global climate change, population growth and increasing consumption, water management is now more than ever a global issue. This paper gives an overview of current and impending water problems while assessing investment needs for integrated water management as a possible solution to projected water challenges. The analysis compares a business as usual case (BAU) to a scenario in which investments improve water efficiency use across sectors to curb demand, increase innovative supply from desalination and enhance conventional water resources management measures. System dynamics modeling is employed to represent the structural factors influencing water demand and supply in the context of an integrated framework including cross-sectoral linkages. The analysis confirms that sustainable water management is feasible, but it requires investments in the range of $\$ 145$ billion per year between 2011 and 2050 (0.16\% of GDP or \$17/person/year) and timely, effective action.
\end{abstract}

Keywords: integrated water resource management; sustainability; system dynamics; T21; water; water management; water policy; water investment 


\section{Introduction}

Economic growth and poverty alleviation are inextricably linked to the access to clean water. Known as the Falkenmark index, there is general consensus that when people have access to less than $1700 \mathrm{~m}^{3}$ of water per year, a considerable proportion of them will be trapped into poverty [1]. Currently 700 million people live under conditions that provide them with less than $1700 \mathrm{~m}^{3}$ of water per year [1]. Water use has also been growing at more than twice the rate of population growth in the last century [2]. Water scarcity, or water stress, is "the point at which the aggregate impact of all users impinges on the supply or quality of water under prevailing institutional arrangements to the extent that the demand by all sectors, including the environment, cannot be satisfied fully" [3]. Although there is no global water scarcity, many countries in arid and semi-arid regions are already exploiting more than $40 \%$ of their renewable sources and an increasing number of regions are chronically short [2].

Even when water is available, inadequate sanitation infrastructure limits the supply of potable water. 1.4 million children under five die each year as a result of lack of access to clean water and sanitation [4]. Many women and children spend a good part of their day fetching clean water instead of generating an income or attending school. Finally, the high price of carted water prevents the poor from investing in other activities [5]. The economic impact of this is huge; the annual loss from insufficient sanitation is approximately USD 6.3 billion in Indonesia, USD 1.4 billion in the Philippines, USD 780 million in Vietnam and USD 450 million in Cambodia (2005 prices). This is approximately 2\% of their combined GDP [6].

Given the importance of water access and sanitation on poverty alleviation, world leaders adopted as one of the Millennium Development Goals (MDG) the task of halving, by 2015, the proportion of the population without sustainable access to safe drinking water and basic sanitation. This has been made more difficult by future increases in demand as a result of population and income growth, changing consumption behavior, and climate change [7]. Rise in global temperatures leading to changes in precipitation are projected to affect the availability of water resources through changes in rainfall distribution, soil moisture, glacier, ice and snow melt, and river and groundwater flows [3]. Although some areas are expected to have an increase in rainfall and run-off, the expected overall effect will be negative [8]. It is estimated that by 2025, around 3 billion people will be affected by water shortages unless action is taken to mitigate climate change and manage water resources sustainably [9].

The challenge then is to assuage the effects of climate change so as not to deepen the world's current water problems, while improving access and managing water resources sustainably in order to maintain long term economic growth and job creation. This paper aims at estimating the amount of funding needed to curb water demand and improve supply so as to transition to sustainability for the water sector. Impacts will also be estimated, assuming that funding allocation translates into effective actions, using available and published cost factors [10]. 


\section{Literature Review}

Integrated optimization models are commonly used to model efficient resource allocation. There are three possible degrees of integration; internal, external and socio-economic [11]. Water models that are internally integrated recognize that water comprises a system of surface and groundwater, quality and quantity, but do not go beyond this [11]. Externally integrated water models link the water system with surrounding fields such as Gilmour, Jakeman and Letcher's model to assess land and water policy options [12]. The most desirable level of integration considers not only the link between water resources and other sectors of the economy but the impact that this has on socioeconomic development and vice versa [11]. An example of this is Croke et al.'s integrated modeling toolbox for catchments, which contains models for crop growth, erosion, rainfall-runoff, household decisions and socioeconomic impact [13]. Another example is A.Y. Hoekstra's AQUA model which aims to include as many of the interrelationships and feedback mechanisms between water, the environment and human beings as possible [11]. Although Croke et al. and A.Y. Hoekstra's models account for dynamic complexity, neither model includes a complete link to all sectors of the economy, society as a whole. Plainly there is a need for research on integrated, dynamic water allocation modeling; this paper aims to fill that gap.

Research on global water allocation is particularly limited. One example is the $O E C D$ Environmental Outlook to 2030 report, which uses a global equilibrium model (ENV-Linkages) linked to a dynamic integrated assessment framework (IMAGE) [14]. ENV-Linkages contains 26 sectors and 34 world regions whereas IMAGE quantifies the relative importance of major processes and interaction in the society-biosphere-climate system [14]. This model projects that $67 \%$ of the world's population ( 5 billion $(\mathrm{Bn})$ ) is expected to be without a connection to public sewerage in 2030 . It also estimates that $44 \%$ of the world is currently living under water stress and an additional $1 \mathrm{Bn}$ people will be living in areas with severe water stress by 2030 [14]. Over half the population affected by severe water stress will continue to be found in the BRICs (Brazil, Russia, India and China) and the main increase in population affected will be in India, China, Africa and the Middle East [14]. The projected annual expenditure on water and wastewater services by 2025 is estimated at USD 600 billion for OECD countries and USD 400 billion for BRIC countries [14]. Achieving the Goal 7 of the Millennium Development Goals (MDG) by 2015 is expected to cost about USD 10 billion per year over 15 years [14]. However, the benefits will outweigh the costs; in developing countries, the economic return will be between USD 5 to USD 28 for each dollar invested. Furthermore, the cost of not meeting this MDG has been estimated at some USD 130 billion per year [13].

Another global model of water management is Simonovic's WorldWater model [15]. The WorldWater model uses the World3 model as a starting point and attempts to represent the continuous dynamic interaction between the human population and global resource base. The water resource sector is integrated with five sectors that drive industrial growth: population, agriculture, economy, nonrenewable resources and persistent pollution [15], but remains overly simplified and loosely integrated.

Some useful comparisons can be made with international institutions' projections for global water resource management. Two such reports are "Charting Our Water Future" by the 2030 Water Resource Group [10] and "Making water a part of economic development: The economic benefits of improved 
water" by Hakan Tropp [6]. The 2030 Water Resource Group finds that under an average economic growth scenario with no efficiency gains, the world demand for water by 2030 will be $40 \%$ above current accessible and reliable supply, taking into account a portion of supply that should be reserved for sustainable management [10]. This is an aggregate value with local gaps reflecting a worse situation [10]. Tropp argues that between 2002 and 2015, access to water and sanitation would have to increase by $1.3 \mathrm{Bn}$ and 1.9 Bn people respectively in order to meet MDG 2015 [6]. Both reports draw the same conclusion; when spread over a number of years and divided by the number of people expected to benefit from such expenditure, the investment case is strong [6,10]. For example, in Ghana, an investment of US\$7.40 per person over a decade would enable this country to meet its MDG target [16]. Tropp estimates that the aggregate cost would be USD $11.3 \mathrm{Bn}$ annually but in return, the total annual accrued economic benefit is expected to be USD $84 \mathrm{Bn}$ with variation among regions. There would also be a gain of 322 million (Mn) working days and USD $750 \mathrm{Mn}$ in value of adult working days as a result of less illness. Finally, the money saved from improved water collection would be USD 64 Bn [6]. The 2030 Water Resource Group did not calculate an aggregate cost but "water marginal cost curves" for particular countries (India, China, South Africa, Sao Paulo) with none of the costs surpassing $0.1 \%$ of their GDP [10]. Therefore the literature seems to suggest that it is imperative, economically viable and economically beneficial to invest in world water resource management and sanitation.

Summarizing the literature review, it is clear that very few studies focus on global water trends despite the fact that the challenges ahead of us require coordinated international action. This is action is required by the relevance of water in the global social, economic and environmental context. The present study aims at providing a global estimate of the investment needed to sustainably supply needed water in the years to come, and examines the impact of selected interventions.

\section{Analysis}

\subsection{Method}

A system dynamics model is developed to represent water demand and supply at the world level, which is embedded in a larger framework to fully appreciate the endogenous linkages within water resources and interaction with a variety of economic, social, and environmental sectors. An econometric approach was coupled with a more systemic representation of the physical factors influencing demand and supply when either data were missing or when the complexity of the system required a level of detail that could not be represented dynamically. The result is a hybrid model that, to a certain extent and still having several limitations, fills certain gaps of both methodologies when used in isolation. Below are presented the key variables used to calculate water demand and supply in the model. A more detailed, variable by variable documentation is available in Bassi et al. [17].

Total water demand is disaggregated into agricultural, industrial and municipal sectors.

$$
D_{t}=A D_{t}+I D_{t}+M D_{t}
$$

Where $D_{t}$ is the current water demand, $A D_{t}$ is agricultural water demand, $I D_{t}$ is industrial water demand, and $M D_{t}$ is municipal water demand. Demand of each sector is modeled as a non-linear function of associated sectoral factors and water use efficiency. 
Relative agricultural water demand is determined by land (relative harvested area $r h_{t}$ ), agricultural total factor productivity $f p a_{t}$. Therefore, agricultural water demand $A D_{t}$ is calculated as:

$$
A D_{t}=A D_{t-1} * r h_{t}^{a} / f p a_{t}^{b} *\left(1-e a_{t}\right)
$$

Where $A D_{t-1}$ is reference agricultural water demand, $a$ is the elasticity of harvested area and $b$ is the elasticity of agricultural total factor productivity. Note that $e a_{t}$ is agricultural water use efficiency gains to additional investment in water demand management. Thus if this investment is not allocated, no additional (on top and above the business-as-usual (BAU) scenario) efficiency improvements is achieved and $e a_{t}$ is equal to zero.

Industrial water demand $I D_{t}$ is formulated similarly, though it depends on industrial production rather than land. The equation is as follows:

$$
I D_{t}=I D_{t-1} * r p i_{t}^{c} / f p i_{t}^{d} *\left(1-e i_{t}\right)
$$

Where $I D_{t-1}$ is reference industrial water demand, $r p i_{t}$ is relative industrial production, $f p i_{t}$ is industrial total factor productivity, and $e i_{t}$ is industrial water efficiency improvement rate driven by additional investment. Moreover, $c$ is the elasticity of industrial production and $d$ is the elasticity of industrial total factor productivity.

Municipal water demand $M D_{t}$, instead, is affected by population and income. The estimation is shown below:

$$
M D_{t}=M D_{t-1}^{*} r p o p_{t}^{e} / \operatorname{rinc}_{t}^{f} *\left(1-e m_{t}\right)
$$

Where $M D_{t-1}$ is reference municipal water demand, $r p o p_{t}$ is relative population, rinc $c_{t}$ is relative GDP per capita as an indicator of income level, and $e m_{t}$ is municipal water efficiency improvement rate driven by additional investment. Moreover, $e$ is the elasticity of population and $f$ is the elasticity of GDP per capita. All the input factors mentioned above (including land, industrial production, income and population) are endogenously simulated. Since their description and explanation goes beyond the focus of this paper, more information can be found in Bassi et al. [17].

Water supply in this study comprises surface and groundwater, water in reservoirs, treated wastewater and potential desalination.

As is illustrated in Figure 1, surface and groundwater stocks are increased by internally produced water from precipitation. The water in reservoirs is determined by their storage capacity, often depending on water demand. Evaporation causes loss of water on surface and in reservoirs. The amount of wastewater treated is influenced by population level and people's disposable income (i.e., investment). Additional water supply from desalination can be obtained if associated investments in innovative supply are allocated. 
Figure 1. Sources of water supply (in blue boxes) and key influencing factors (in grey). Investment options in water supply management (conventional and innovative) are highlighted in orange. The water flows between various sources are presented in thick blue arrows, while green ones indicate impacts of key factors on water resources.

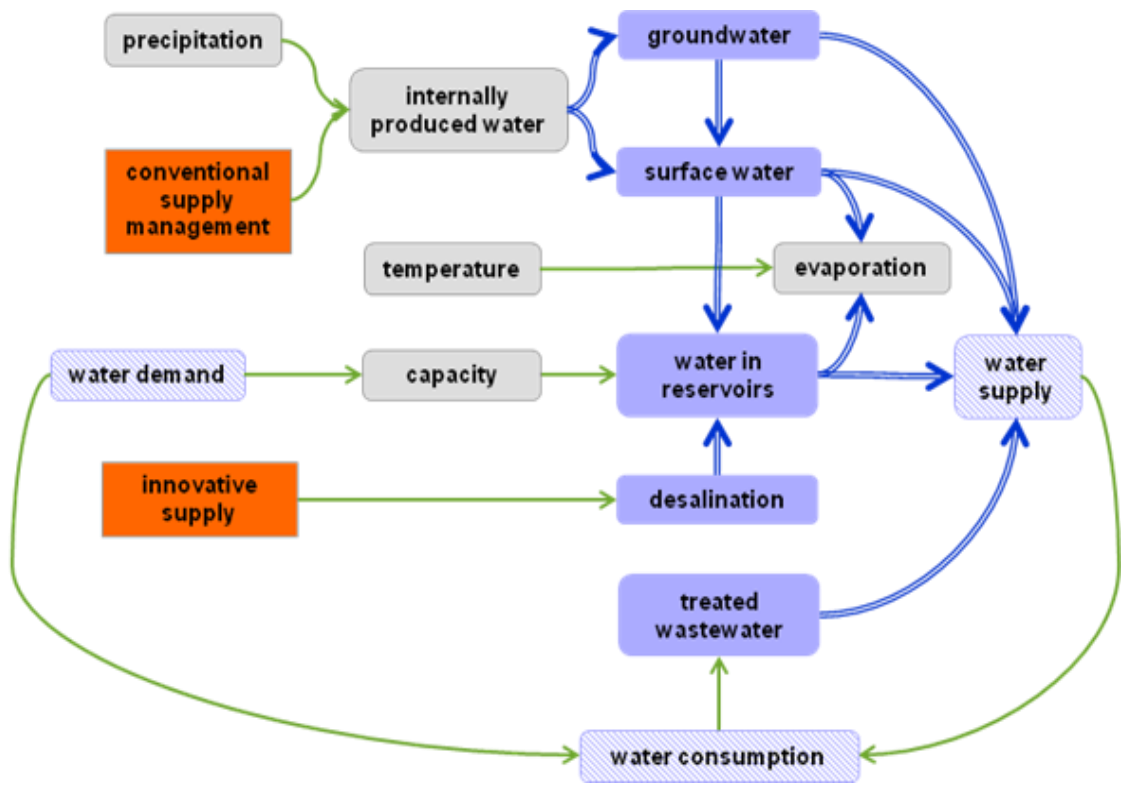

Finally, to estimate the availability of water resources, water stress $w s$ is defined as the ratio of water demand $D_{t}$-calculated above- over total renewable water resources $R W R_{t}$ :

$$
\begin{gathered}
w s=D_{t} / R W R_{t} \\
R W R_{t}=I P W_{t}+E V P_{t}
\end{gathered}
$$

Where $I P W_{t}$ is internally produced water and $E V P_{t}$ is surface evaporation.

Note that, water stress tend to lower agricultural and industrial productivity, which, as described above, influence water demand in turn.

\subsection{Assumptions}

The Business-As-Usual (BAU) case of the T21-World model used in this study is modeled on the assumption that current trends will continue, with no fundamental changes in policy or external conditions (e.g., continued unsustainable exploitation of natural resources). This scenario is set up and calibrated to consistently reproduce baseline projections of existing sectoral models and reports on population, economy and water, among others. These include, relevant to water sector, United Nations' World Population Prospects (WPP) [18], World Bank's World Development Indicators (WDI) [19], OECD's Environmental Outlook to 2030 [14], and McKinsey's Charting Our Water Future [10] reports.

Alternatively, the integrated water management (IWM) scenario assumes the allocation of \$144 Bn (or $0.16 \%$ of GDP) of additional investments to the water sector per year on average between 2010 and 2050 to achieve the arbitrary target of limiting water demand to $6,000 \mathrm{~km}^{3}$ in 2050 and curbing the projected growth of water stress. These investments expand the access to potable water and water services, improve water use efficiency, increase water supply through desalination and more conventional management measures. The breakdown of investments is given below: 
1. In order to meet the MDG of halving the proportion of people without access to clean water by 2015 , the investment of $\$ 18.4 \mathrm{Bn}$ per year is allocated between 2011 and 2050 to improve the access to potable water and water services, accounting for $13 \%$ of the additional investments associated to water sector. The cost used is based on recent estimates that the amount needed to deliver the 2015 MDG for developing countries is US\$14.2 billion per annum for sanitation and US\$4.2 billion for drinking water supply to households [20].

2. To improve water efficiency, it is assumed that $\$ 66.4 \mathrm{Bn}$ per annum (46\% of water investment) on average over the next 40 years will be needed in water demand management, with a unit cost of $\$ 0.08 / \mathrm{m}^{3}$, based on McKinsey's report [10].

3. The remaining (41\%) investment ( $\$ 58.8 \mathrm{Bn}$ per annum on average between 2010 and 2050) aims to increase water supply, which is further disaggregated into innovative and conventional water supply:

○ Desalination: $30 \%$ of water supply investment will be invested in innovative water supply from desalination. The unit cost to increase supply of desalinated water is set at $\$ 0.8 / \mathrm{m}^{3}[10]$.

○ Conventional water supply management: $70 \%$ of the water supply investment is allocated to conventional water supply management measures. The unit cost to increase conventional water supply is set at $\$ 0.08 / \mathrm{m}^{3}[10]$.

\subsection{Results}

If no new measures are taken to reduce demand, under a BAU scenario, total water supply (currently at $4,800 \mathrm{~km}^{3}$ ) is projected to increase by $41 \%$, reaching $8,105 \mathrm{~km}^{3}$, between now and 2030 (in line with 2030 Water Resource Group projections)-primarily driven by world population and GDP growth, and mitigated by an increase in agriculture productivity.

While demand from all main economic sectors is on the rise in the BAU scenario, the agriculture sector will remain the single largest consumer, with its water withdrawal rising from $3,449 \mathrm{~km}^{3}$ today to $4,322 \mathrm{~km}^{3}$ by 2030 and is expected to rise to $5,192 \mathrm{~km}^{3}$ by 2050 . This actually represents a decline in the total share of water demand from $70 \%$ to $58 \%$ of total withdrawals. The share of municipal water demand will increase from $12.4 \%$ today to $13.5 \%$ in 2050 due to population growth being concentrated in urban centers [21]. On the other hand, the share of industrial water demand to total water demand is expected to increase even more from $17.2 \%$ in 2009 to $28 \%$ by 2050.

In such a case, unsustainable water withdrawals will cause the ground water stock to decrease by $11 \%$ compared to current levels and surface water to reduce by $6 \%$. This will require massive global shifts in sources of water withdrawal if there is no increase in supply from desalination, with water stress reaching over $67 \%$ of the population.

In order to relieve the rising water stress worldwide under the IWM scenario, a total investment of $\$ 144 \mathrm{Bn}$ per annum is allocated to the water sector over the next forty years in both efficiency measures on the demand side and supply measures from traditional and innovative sources will be taken. This will indirectly affects agricultural, biofuel and industrial production. 
Results of the simulation indicate that the investments in integrated water management contribute to increasing water supply up to $6,700 \mathrm{~km}^{3}$ by 2050 . This includes about $30 \mathrm{~km}^{3}$ supplied from water desalination in 2050, while the remaining supply derive from other sources, including treated wastewater, reservoirs, and surface and groundwater, intended to take place primarily in areas characterized by severe water stress. However, its contribution would be limited to about $8 \%$ of total demand in 2050, if no measures are taken on the demand side. When constructing large-scale water related infrastructures such as dams, their negative effects on the hydrologic cycle should be taken into account. They are believed to reduce return flow of water to the original source that allows for use by people and habitats downstream [22]. When rivers are dammed or diverted, there is no return flow to regenerate the river downstream, destroying ecosystems as well as economies [23].

On the demand side, with the efficiency improvement of municipal water use, the total water demand will increase at a considerably slower pace in the long run, reaching $5,657 \mathrm{~km}^{3}$ in 2030 , and $6,000 \mathrm{~km}^{3}$ in 2050 (26\% below BAU). Worth noting, agriculture demand decreases considerably ( $41 \%$ reduction by 2050 relative to BAU) due to reduced harvested land -driven by increases in productivity- and specific investments in water efficiency. Industrial demand instead grows slightly above BAU (by $3 \%$ in 2050), primarily pushed by higher GDP in the alternative scenarios simulated, which offsets the projected $27 \%$ gain in water efficiency.

As a result of both water saving efforts on the demand side and incremental supply from conventional and innovative water sources under the IWM scenario, total water supply is expected to be able to satisfy future overall global demand, with of course possible exceptions at a more regional and localized level. Additionally, the stocks of ground water and surface water are projected to be higher than baseline by $3 \%$ in forty years, reversing their historical declining trend. Due to the reduction in total water consumption, and assuming that improved water efficiency does not generate new jobs (data are missing in this respect) water sector employment is projected to be about $26 \%$ lower than BAU, reaching $39 \mathrm{M}$ in 2050. Finally, the improved management of water resources will also reduce the share of population under water stress to $60.9 \%$ from $67.4 \%$ in the BAU case, showing tendency to level off in the longer term.

Comparing the simulation results in this study to other reports, the past and future BAU projections of the model fit well with the water withdrawal values from McKinsey [10], with an R-square of $97.6 \%$ and difference in standard deviation of $0.16 \%$ for total water withdrawal. In terms of sectoral water use, the R-square and standard deviation are in the range of $93 \%$ to $99.9 \%$, and $0.1 \%$ to $0.3 \%$ respectively. The future projections for the alternative scenario, employing existing published cost figures, when using similar investment values generate results in line with McKinsey [10] and the OECD Environmental Outlook [14]. Overall, assuming that funding allocation translates into effective action could be seen as a limitation of the modeling work, but it also allow for higher structural validation and confidence in projected trends.

As noted earlier, the three largest sources of water demand are the agriculture sector, municipalities and industry. In the following three subsections, a brief discussion of water management in these sectors is given due to their particular importance in global water management. 


\subsubsection{Agriculture}

As the primary source of food production and water use, agriculture is one of the most important sectors of the economy. This sector uses $70 \%$ of global water withdrawals [24] and accounts for $60 \%$ of the world's livelihood [25]. Under the BAU scenario, agricultural production is projected to increase due to population growth and change in consumption behavior, but at a decreasing rate. This will put increased pressure on water resources. Growth in production will come from higher yields, cropping intensity and land expansion. If higher yields are a result of an increase in (inorganic) fertilizer use then soil quality can be expected to decline. Poor soil quality reduces the ability of soil to hold water which increases run off, decreasing water productivity and availability [26]. Furthermore, the use of nitrogen fertilizers worsens climate change as nitrous oxide is 310 times greater in its global warming capacity than carbon dioxide [27]. Rise in global temperatures will likely exacerbate water shortages as a result of increased evaporation in many regions of the world. Agricultural land expansion will go from $4.9 \mathrm{Bn}$ ha in 2009 to $5.4 \mathrm{Bn}$ ha in 2050, mainly at the sacrifice of forests. Natural forests and wetlands can serve as water purification, groundwater recharge, carbon sink and buffers against extreme weather, and provide water for major cities and densely populated rural areas [28,29]. Several studies have shown that deforestation in the Amazon will result in a less intense water cycle [30,31]. One notable historical change under BAU is the increase in the total land area under organic agriculture by $3 \%$ between 2000 and 2006 at the world level [32]. Organic agriculture uses organic biomass and biological $\mathrm{N}$-fixing to fertilize crops, which improves soil quality, increasing the retention of water in soil and increasing water productivity.

Under the IWM scenario, additional investments are allocated to increase agricultural water productivity through a mix of water use efficiency measures (e.g., increased drip and sprinkler irrigation and adoption of irrigation scheduling), development of supply infrastructure and technology to increase water availability and sustainable farming practices. Such practices, requiring more investments for implementation (see Bassi et al. [33]), include long-term soil quality improvement through transition to conservation tillage farming and protection of natural ecosystems, and reduction in harvest losses as due to better pest management and post harvest management. As a result of these synergic measures, total agriculture production (including fishery and forestry) will increase by $15 \%$ relative to BAU in forty years. This will increase water consumption but less so compared to BAU. Agricultural demand for water per ha will be reduced by $20 \%$ and $39 \%$ relative to BAU in 2030 and 2050. In total, this represents a $26 \%$ reduction in water demand from global agriculture. Increased precipitation and accelerated water cycles relative to BAU can be expected due to reduced deforestation as harvested area plateau around 1.26 Bn ha after 2027 (opposed to BAU at 1.3 Bn ha in 2050). Finally, the IWM scenario is expected to see the introduction and expansion of second generation biofuels which use agricultural residues and marginal land as opposed to using fertile agricultural land for first generation biofuels. Therefore, using agricultural residues will save the water normally used for first generation biofuels.

However, it is worth noting that in very efficiently irrigation fields, no excess water seeps into the ground to replenish aquifers, which reduces the available water to other users [22]. Therefore, it should be ensured that these additional investments must outweigh their long term environmental cost. 


\subsubsection{Municipal}

Under BAU, the share of municipal water demand is projected to increase from $12.4 \%$ today to $13.5 \%$ in 2050 as a result of population growth being concentrated in urban areas, and growing per capita income. Municipalities consume over three fourths of natural resources and are the cause of $75 \%$ of all energy use and energy related GHG emissions. Despite this, municipalities concentrate people, processes and interactions, so that they disproportionately increase social and economic opportunities as well as having the potential to optimize a vast range of services [34]. This translates into better environmental performance of municipalities compared to their regional context: New York City produces only 1 per cent of the US greenhouse gases (GHG) but is home to 3.7 per cent of its population [35]. With the additional investment in municipal water efficiency, the sectoral water demand will be reduced by $6 \%$ in 2050 , or by $7 \%$ in terms of average demand per capita. Possible measures include innovation of end-user technologies (e.g., plumbing fixtures), installation and rehabilitation of efficient equipment and increased water-saving awareness of the population [10].

Residential water use (RWU) constitutes well over half of the municipal water use in many countries and requires higher quality and reliability, which often means higher costs [36]. Brown and Zhang found that there are several factors which affect residential water demand which should be kept in mind when considering policy options to assuage unsustainable use of water: policy variables (e.g., water price or rate), household economic variables (e.g., income), physical features and technological variables (e.g., water amenities and metering), environmental variables (e.g., temperature and precipitation) and demographic variables (e.g., household size and attitudinal variables) [36]. However, residential water use is but one element in municipal water management and lack of relevant data on the world's cities, especially with regards to slums, prevents the creation of meaningful municipal water policies. Bassi et al. have successfully identified factors contributing to municipal, industrial and agricultural water demand and supply of Maui, which were integrated into a dynamic model [37]. These two analyses provided a valuable starting point for understanding global water management in municipalities, but gaps remain.

\subsubsection{Industrial}

One of the key features of expected projections of water demand is the rate of growth in demand from the industrial sector. Water for industry (and for the electric power sector) is increasingly competing with water needs by agriculture and urban consumers [26]. Water treatment is a necessary precondition for industrial (or consumer) water use, and large cities like London or Beijing may have to recycle their water intake several times before final release [26]. About half of the industrial water use is for cooling purposes, and about a third of this water is lost as vapor, but much of the other two thirds can be used downstream (although the heat content can be harmful to aquatic ecosystems) [26]. Other industrial water uses include quenching hot coke or red hot steel ingots, wood pulping, washing, rinsing and dyeing of textiles, tanning of leather and surface finishing (including electroplating). These uses leave polluted and sometimes toxic waste streams that need treatment, which uses even more water [26].

On the other hand, the IWM scenario is expected to see reduction in industrial water use. In addition to investing in more efficient industrial technologies and equipment, recycling wastewater is 
viable option. The world market in 2008 was $\$ 374 \mathrm{~B}$, of which $\$ 70 \mathrm{~B}$ was in the US alone [26]. The water treatment market is currently about $\$ 300 \mathrm{~B} / \mathrm{year}$ and $50 \%$ of this market could be served by high performance modular systems, using magnetic separation technology, that have been developed in recent years [26]. Magnetic separation techniques have been successfully applied to both mining and industrial wastes and, recently, to municipal wastewater [38,39]. These techniques are just at the beginning of what could be a major revolution in water treatment.

Water from wood pulping is mostly recycled internally to recycle the chemicals, but metallurgical, chemical, textile and other surface finishing operations generate quite a lot of polluted wastewater that must be treated before it can be re-used [26]. There are technologies that allow for the treatment of this water, but in the longer term, there are numerous possibilities for making the processes themselves more efficient or cleaner [26]. In particular, the need for industrial cooling water can and should be reduced dramatically by introducing co-generation of electricity to take advantage of high temperature heat that is currently wasted [26].

In many cases, the most cost-effective solution to this expected increase in water demand is to transfer water from the agricultural sector. Significant transfers of water from rural to urban areas can be expected in China and in North America [10].

Considering the nexus between water and energy, the increasing use of renewable energies (such as such as solar, wind, and hydropower) as a solution to GHG emissions will mitigate the water pollution from industrial production (or power generation), and can lead to potential reduction in consumptive water use. Table 1 shows the lower water use per unit of electricity produced from alternatives than traditional sources in the US. Therefore, the development these renewable technologies in the energy sector may also contribute to the sustainable management of water resources. However, it cannot be assumed that using renewable source of energy is always better for the environment and there is an associated water cost that is often overlooked. Hydroelectricity, for instance, has a natural drawback of high evaporation due to the conformation of dams and artificial lakes. It also needs to be considered that options like carbon capture and sequestration (CCS) seem to require more water than conventional plants with no CCS capability.

Table 1. Liters of water used per kWh of electricity generation from different energy sources (U.S.).

\begin{tabular}{|l|l|}
\hline Energy Source & Liter/kWh \\
\hline Nuclear & 2.3 \\
\hline Coal & 1.9 \\
\hline Oil & 1.6 \\
\hline Combined cycle & 0.95 \\
\hline Photovoltaic panels & 0.11 \\
\hline Wind & 0.004 \\
\hline
\end{tabular}

Source: American Wind Energy Association, 1995 [40]. 


\section{Key Considerations for Implementing Water Investment and Policy}

Effective political arrangements are necessary to ensure successful investments in the transition. Market distortions such as water-wasteful subsidies and lack of property rights that is believed to result in inefficient resource allocation should be removed [5,41]. The introduction of externalities or incentives could discourage polluting and inefficient behaviors and motivate the alternatives. Carbon pricing, for example, is expected to reduce leakage and encourage installation of irrigation scheduling systems [5], whereas high management costs of water resource preservation can be reduced by incentive to change consumptive and attitudinal behavior towards less water-intensive products, more efficient water use, and more open to using reclaimed wastewater. However, in the short term, there is a disincentive for many countries to reflect the full cost of resource depletion, pollution and input subsidies because of the cost that it will incur on their economies and the fear of being less competitive. Labor leaders in the United States argue that policies should not encourage offshoring of manufacturing or the sale a of assets, and warn against "carbon leakage", which results when companies move their production to regions of the world without comparable GHG emissions reduction commitments [42].

Institutional arrangements also need to be developed to manage and regulate the adoption of a variety of water-related measures. The World Bank also identifies the institutional aspects that most contribute to water sector performance, which is useful when targeting potential reforms. These include the integrated legal treatment of water sources, the existence of an independent body for water pricing, the balance of functional specialization, the legal scope for private participation and the seriousness of the budget constraint. On the contrary, poor arrangements can be a constraining factor on implementing water policy successfully. It may be a problem of multiple stakeholders being involved that causes fragmentation of institutional responsibility, or a lack of integrated water policies, inconsistent water law and other similar factors. A detailed report by the World Bank recognized that policy makers know that there are heavy socio-economic costs associated with institutional adequacy but that political economy constraints are a powerful obstacle for implementing reform [43].

\section{Conclusions}

Water is a vital component of the earth's ecosystem and input in economic activities and people's livelihood, which has in turn imposed consistently growing pressure on water resources through increasing over-withdrawal and pollution, leaving some one-third of the world's population under water stress. In face of severe global water challenge, this paper analyzes the impacts of integrated water management by investing in a mix of water saving (through efficient use) and supply gains (through better management measures and nonconventional sources).

To support the analysis, system dynamics modeling work was undertaken to examine world water demand and supply trends within an integrated economic, environmental and social system. We estimate that it will cost about \$144 Bn per year between 2011 and 2050 (or $0.16 \%$ of GDP on average per year) in water management on both demand and supply sides to achieve the target of limiting water demand to $6,000 \mathrm{~km}^{3}$ in 2050 and curbing the projected growth of water stress. Under this scenario we estimate that there will be sufficient water supply to meet future water demands, which allows a $27 \%$ 
reduction in water stress over a forty-year period, releasing about $6.6 \%$ of total population from water stress compared to BAU.

These positive results are a consequence of investments in improved water efficiency use across sectors, improved infrastructure and increased supply through desalination and more conventional measures. As water availability is among the main factors influencing productivity, the benefits go beyond the water sector, mitigating climate change and enhancing the adaptation capacity to spurred economic growth beyond the BAU case. Thus investments in water management appear to be a viable global option, bringing far reaching benefits. While the absolute cost may seem large, when spread across the population (\$17/person/year) and the forty-year period analyzed -taking into account the cross-sectoral gains, the return on investment is considerable. More importantly, the cost of not allocating these incremental investments is very large in monetary and human value, particularly in the medium to longer run.

The successful implementation of investments requires effective political and institutional arrangements. The most difficult task is to get world leaders to act in the long-term interest of not just their own people but the world's people. This paper confirms that there is enough water available to meet future demand but only if action is taken soon to mobilize the needed investments. Comparing BAU and IWRM scenarios, in fact, shows that waiting would increase the cost of interventions needed to limit water stress, among others. Overall, if world leaders do not act, or if the effects of climate change are worse than our projections suggest, dramatic changes will have to take place to avoid a water crisis.

\section{Acknowledgements}

The authors would like to acknowledge the financial support provided by the United Nations Environment Program (UNEP) for the creation of the model used to carry out this analysis.

\section{References}

1. Falkenmark, M. The massive scarcity now threatening Africa: Why isn't it being addressed? Ambio 1989, 18, 112-118.

2. Food and Agricultural Organization of the United Nations (FAO) - Water. Treated Water Reuse; Available online: http://www.fao.org/nr/water/topics.html (accessed on 10 June 2010).

3. United Nations - Water. Key Messages on Climate Change and Water; prepared for COP 15; UN Division for Sustainable Development, Department of Economic and Social Affairs: New York, NY, USA, 2009; Available online: http://www.unwater.org/downloads/UNWclimatechange_EN.pdf (accessed on 10 August 2010).

4. The United Nations Children's Fund (UNICEF). The State of the World's Children 2005: Childhood under Threat; UNICEF: New York, NY, USA, 2004.

5. United Nations Environment Programme (UNEP). Green Economy Report: A Preview; United Nations Environment Programme: Nairobi, Kenya, 2010.

6. Tropp, H.; Tropp, H.; Berntell, A. (2005); Making Water a Part of Economic Development: The Economic Benefits of Improved Water Management and Services; Prepared for the UNEP Green Economy Report, 2010; Stockholm International Water Institute: Stockholm, Sweden, 2010. 
7. Organisation for Economic Cooperation and Development (OECD). Managing Water for All: An OECD Perspective on Pricing and Financing; OECD: Paris, France, 2009.

8. International Food Policy Research Institute (IFPRI). Climate Change: Impact on Agriculture and Costs of Adaptation 2009. Food Policy Report 21; Nelson, G.C., Rosegrant, M.W., Koo, J., Robertson, R., Sulser, T., Zhu, T., Ringler, C., Msangi, S., Palazzo, A., Batka, M., Magalhaes, M., Valmonte-Santos, R., Ewing, M., Lee, D., Eds.; IFPRI: Washington, D.C., USA, 2009.

9. Poverty Environment Partnership (PEP). Linking Poverty Reduction and Water Management; United Nations Development Programme (UNDP) and the Stockholm Environment Institute (SEI) on behalf of PEP; SEI: Stockholm, Sweden, 2006.

10. 2030 Water Resources Group. Charting our Water Future: Economic Frameworks to Inform Decision Making; McKinsey \& Company: Washington, D.C., USA, 2009.

11. Hoekstra, A.Y. Water supply in the long term: A risk assessment. Phys. Chem. Earth Par. BHydrol. OC. 2000, 25, 221-226.

12. Gilmour, J.K.; Jakeman, A.J.; Letcher, R.A. Analysis of an integrated model for assessing land and water policy options. Math. Comput. Sim. 2005, 69, 57-77.

13. Croke, B.F.W.; Jakeman, A.J.; Letcher, R.A. Integrated assessment modeling for water resource allocation and management: A generalized conceptual framework. Environ. Modell. Softw. 2007, $22,733-742$.

14. Organisation for Economic Cooperation and Development (OECD). Environment Outlook to 2030; OECD: Paris, France, 2008.

15. Simonovic, S.P. World water dynamics: Global modeling of water resources. J. Environ. Manage. 2002, 66, 249-267.

16. Sanctuary, M.; Tropp, A; Berntell, A. Making Water a Part of Economic Development: The Economic Benefits of Improved Water Management Services; Stockholm International Water Institute: Stockholm, Sweden, 2005.

17. Bassi, A.M.; Pedercini, M.; Ansah, J.P.; Tan, Z. T21-World Model Documentation, Modeling the Green Economy; Millennium Institute: Arlington, VA, USA, 2010.

18. United Nations Population Division (UNPD). World Population Prospects: The 2008 Revision; UNPD: New York, NY, USA, 2009.

19. World Bank. World Development Indicators Database. Available online: http://data.worldbank.org/indicator (accessed on 13 October 2009).

20. United Nations Population Division (UNPD). World Urbanisation Prospects, 2007 Revision; UNPD: New York, NY, USA, 2008.

21. Hutton, G.; Bartram, J. Global costs of attaining the millennium development goal for water supply and sanitation. Bull. WHO 2008, 86, 1-80.

22. Molden, D. Accounting for Water Use and Productivity. SWIM Paper 1; International Irrigation Management Institute: Colombo, Sri Lanka, 1997.

23. Postel, S. Water for life, guest editorial. Front. Ecol. Environ. 2009, 7, 63-63.

24. Molden, D. Water for Life, Water for Good: A Comprehensive Assessment of Water Management in Agriculture; Earthscan: London, UK; International Water Management Institute: Colombo, Sri Lanka, 2007. 
25. International Assessment of Agricultural Knowledge, Science, and Technology for Development (IAASTD). Agriculture at a Crossroads, Synthesis Report; Island Press: Washington, D.C., USA, 2009.

26. Ayers, R.S; Westcot, D.W. FAO Irrigation and Drainage Paper \#29: Water Quality for Agriculture; Food and Agriculture Organization of the United Nations (FAO): Rome, Italy, 1985.

27. Food and Agriculture Organization of the United Nations (FAO). Global Forest Resource Assessment, 2005; FAO: Rome, Italy, 2006.

28. Bjørndalen, J.E. Tanzania's vanishing rain forests: Assessment of nature conservation values, biodiversity and importance for water catchment. Agr. Ecosyst. Environ. 1992, 40, 313-334.

29. Komatsu, H.; Kume, T.; Otsuki, K.; Shinohara, Y. Relationship between annual rainfall and interception ratio for forests across Japan. Forest Ecol. Manage. 2008, 256, 1189-1197.

30. D’Almeida, C.; Dingman, S.L.; Hurtt, G.C.; Keim, B.D.; Marengo, J.A.; Vörösmarty, C.J. A water balance model to study the hydrological response to different scenarios of deforestation in Amazonia. J. Hydrol. 2006, 331, 125-136.

31. Bunyard, P. The real importance of the Amazon rain forest. Sci. Soc. 2010, 46, 14-18.

32. International Federation of Organic Agriculture Movements (IFOAM); Research Institute of Organic Agriculture (FiBL). The World of Organic Agriculture: Statistics and Emerging Trends 2008; IFOAM: Bonn, Germany; FiBL: Frick, Switzerland, 2008.

33. Bassi, A.M.; Herren, H.R.; Tan, Z.; Saslow, B. Assessing future prospects of the agriculture sector using an integrated approach. Sustainability 2010 (Submitted).

34. Carruthers, J.; Ulfarsson, G. Urban sprawl and the cost of public services. Environ. Plan. B-Plan. Design 2003, 30, 503-522.

35. PlaNYC (2007). A Greener, Greater New York; Available online: http://www.nyc.gov/html/ planyc2030/html/downloads/download.shtml (accessed on 10 July 2010).

36. Brown, D.F.; Zhang, H.H. Understanding urban residential water use in Beijing and Tianjin, China. Habitat Int. 2005, 29, 469-491.

37. Bassi, A.M.; Harrisson, J.; Mistry, R. Using an integrated participatory modeling approach to assess water management options and support community conversations on Maui. Sustainability 2009, 1, 1331-1348.

38. Kolm. H.H.; Oberteuffer, J.; Kelland, D. High gradient magnetic separation. Sci. Am. 1975, 223, 46-54.

39. Svoboda, Jan. Magnetic Techniques for the Treatment of Materials (Advances in Global Change Research); Kluwer Academic: Dordrecht, The Netherlands, 2004; pp.656.

40. American Wind Energy Association. How much water do wind turbines use compared with conventional power plants? Available online: http://www.awea.org/faq/water.html (accessed on 19 June 2010).

41. Ansink, E.; Weikard, H-P. Contested water rights. Eur. J. Polit. Econ. 2009, 25, 247-260.

42. Bassi, A.M.; Yudken, J.S.; Ruth, M. Climate policy impacts on the competitiveness of energy-intensive manufacturing sectors. Energy Policy 2009, 37, 3052-3060. 
43. Saleth, R.M.; Dinar, A. The Institutional Economics of Water A Cross-Country Analysis of Institutions and Performance; World Bank Publications: Washington, D.C., 2004.

(C) 2010 by the authors; licensee MDPI, Basel, Switzerland. This article is an open access article distributed under the terms and conditions of the Creative Commons Attribution license (http://creativecommons.org/licenses/by/3.0/). 